ISSN 1518-3483

\title{
Currículo e avaliação: duas faces da mesma moeda na garantia do direito à educação de qualidade social
}

Curriculum and evaluation: two sides of the same coin in guaranteeing the right to education with social quality

\author{
Plan de estudios y evaluación: dos caras de la misma \\ moneda en la garantía del derecho a \\ la educación de calidad social
}

\author{
Ana Maria Eyng* \\ Pontifícia Universidade Católica do Paraná (PUCPR), Curitiba, Paraná, PR, Brasil
}

\section{Resumo}

O direito à educação de qualidade social viabiliza-se a partir do estreito e permanente diálogo entre os pressupostos do currículo pós-crítico e da avaliação emancipatória. Com base nesse pressuposto, consideramos, para análise, a relação entre políticas de currículo e avaliação,

AME: professora, doutora em Educação, e-mail: eyng.anamaria@gmail.com 
considerando a questão: que concepções sobre currículo e avaliação transitam no espaço escolar e que efeitos produzem no jogo de forças que atuam mantendo práticas conservadoras no espaço escolar? A análise se baseia em elementos teórico-metodológicos advindos de pesquisa bibliográfica em diálogo com dados empíricos, cuja coleta foi realizada via aplicação de entrevistas individuais estruturadas com crianças e adolescentes. Na discussão, são contempladas a avaliação emancipatória, inspirada em Saul (1988), e a perspectiva pós-crítica do currículo, referendada em Silva (2009) e Eyng (2010), que se perfilam entre os condicionantes da garantia do direito à educação, conforme Santos (2010), Estevão (2013), como parâmetro à qualidade social, segundo análise de Silva (2009). Os requisitos da educação de qualidade social incluem currículos interculturais avaliados de forma emancipatória. A garantia do direito à educação, como possibilidade emancipatória, requer uma política contra-hegemônica, considerando a efetivação da qualidade social para todos e todas.

Palavras-chave: Avaliação emancipatória. Currículo pós-crítico. Direito à educação. Qualidade social.

\begin{abstract}
The right to education with social quality is enabled by a close and constant dialogue between the assumptions of post-critical curricula and emancipatory evaluation, considering the question: what conceptions of curriculum and assessment are carried over at school and what are the effects on the game of forces that maintain conservative practices at school? The analysis is based on methodological theoretical elements from literature in dialogue with empirical data, whose collection was performed via application of structured individual interviews with children and adolescents. The discussion contemplates emancipatory evaluation, inspired by Saul (1988), and a post-critical perspective of curriculum, referenced in Silva (2009) and Eyng (2010), which emerge among the conditions guaranteeing the right to education, according to Santos (2010), Estevão (2013), as a parameter for social quality, according to analysis by Silva (2009). The social quality education requirements include intercultural curricula evaluated in an emancipatory way. Ensuring the right to education, as an emancipatory possibility, requires a counter-hegemonic policy, considering the effectiveness of social quality for everyone.
\end{abstract}

Keywords: Emancipatory evaluation. Post-critical curriculum. Right to education. Social quality. 


\section{Resumen}

El derecho a una educación de calidad social, é hecho viable desde el diálogo estrecho y permanente entre los supuestos del plan de estudios post-crítico y de la evaluación emancipadora. Sobre esa base, creemos, para el análisis, la relación entre las políticas curriculares y de evaluación, teniendo en cuenta la pregunta: ¿Qué concepciones de currículo y evaluación prorrogados en la escuela y cuáles son los efectos en el juego de fuerzas que actúan manteniendo prácticas conservadoras en la escuela? El referéndum análisis sobre los elementos teóricos metodológicos de la literatura en el diálogo con los datos empíricos, cuya colección fue realizada a través de la aplicación de entrevistas individuales estructuradas con niños y adolescentes. En la discusión se contemplan la evaluación emancipadora, inspirada por Saúl (1988), y la perspectiva post-crítica de el plan de estudios, refrendada en Silva (2009) y Eyng (2010), que se encuentran entre las limitaciones de garantía derecho a la educación, de acuerdo con Santos (2010), Estevão (2013), como un parámetro a la calidad social, según el análisis por Silva (2009). Los requisitos de la educación de calidad social requieren programas de estudio intercultural evaluó camino emancipatorio. Garantizar el derecho a la educación, como posibilidad emancipatoria, requiere una política contra-hegemónica, teniendo en cuenta la eficacia de la calidad social para todos.

Palabras Clave: Evaluación emancipadora. Plan de estudios post-crítico. Derecho a la educación. Calidad social.

\section{Introdução}

As faces das moedas são fundidas, tornadas uma mesma coisa, objeto físico e signo de valor. Assim pensamos a indissociabilidade currículo-avaliação, que se funde no movimento contínuo do processo educativo. Essa constatação, como conceito, é mais ou menos consensual; mas como plano e intencionalidade materializada, nem tanto.

A frágil relação entre teoria curricular e prática avaliativa na práxis pedagógica suscita a questão que levou à análise apresentada neste artigo. Que concepções sobre currículo e avaliação transitam no espaço 
escolar e que efeitos produzem no jogo de forças que atuam mantendo práticas conservadoras no espaço escolar?

As práticas revelam concepções diversas e, por vezes, a falta delas, como ocorre nos casos em que as ações curriculares desenvolvem-se num movimento que alimenta avaliações estereotipadas e desconexas com os pressupostos teóricos curriculares. E essas mesmas ações se realimentam; não na reflexão sobre os dados da avaliação, mas no próprio ativismo da ação, levando à atividade pela atividade, justificada pelo hábito, pela tradição reprodutora. Por outro lado, uma miscelânea de concepções sobre currículo e avaliação transita no campo pedagógico, das quais alguns fragmentos são pinçados, unidos a outros e aplicados, sem a necessária análise crítica e contextualizada. Essa desconexão e miscelânea atuam dificultando ou impedindo que das concepções sejam feitas as ações na perspectiva da justiça curricular, que possa efetivar a qualidade social da educação via práticas pedagógicas pautadas no diálogo entre a diversidade no currículo e a avaliação emancipatória.

São colocadas em discussão três categorias de análise: a qualidade social, o currículo e a avaliação. As questões são discutidas com referência nos estudos de Candau (2013), Estêvão (2013), Eyng (2010), Leite (2006), Santos (2010), Saul (1988) e Silva (2007, 2009). Os requisitos da educação de qualidade social requerem currículos interculturais avaliados de forma emancipatória.

\section{Currículo, avaliação e qualidade social: aproximações}

A justiça social parametriza a concepção de uma educação básica de qualidade para todos. Na perspectiva contemporânea, isso implica na discussão das questões políticas, econômicas e culturais que incidem na configuração do espaço escolar e, consequentemente, no modo como as relações de poder e as identidades são concebidas, atravessam os currículos e incidem na avaliação.

A compreensão do jogo de forças que produz as práticas educativas nas escolas requer análise dessas múltiplas causalidades e implicações 
e, a partir dessa compreensão, podem-se esboçar possibilidades para assumir o compromisso de tornar, de fato, a educação básica de qualidade para todos. Desse modo, "[...] atualmente exige-se que a educação não valorize apenas a racionalidade ou as racionalidades, mas que aposte também na emoção, nos afetos, nos desejos, no corpo" (ESTÊVÃO, 2013, p. 22).

Entre as implicações dessas exigências contemporâneas, temos a necessidade da problematização das concepções e práticas do currículo e da avaliação que considerem essencialmente os sujeitos e contextos em que convivem e, espera-se, que aprendam. Isso, "[..] obriga, na verdade, a encarar a aprendizagem, sobretudo como um processo de compromisso com o 'outro', com a razão e com os direitos humanos numa distribuição igual das oportunidades e perspectivas de vida (OLSSEN, 2004, p. 26-27)” (ESTÊVÃO, 2013, p. 23).

Nesse sentido, três consequências são intencionadas: a primeira é a assunção de que "[...] a aprendizagem deve ser um compromisso político e social numa comunidade global, constituindo 'uma forma de participação política e democrática” (ESTÊVÃO, 2013, p. 23). Como segunda consequência, espera-se que na escola seja possível a formação da cidadania ativa, como fator de proteção da dignidade humana.

[...] praticar uma pedagogia e uma formação na qual o aprendente é encarado não como um cidadão aprendente, tendo em vista as necessidades do mercado, mas como um aprendente que, através da formação e da aprendizagem, potencia a sua cidadania em prol da dignidade de si e dos outros (ESTÊVÃO, 2013, p. 23).

A terceira consequência torna-se condição para que as duas primeiras possam ser objetivadas: a problematização, a discussão e a construção de significados mais apropriados e consistentes sobre currículo e avaliação, de modo a consubstanciarem práticas pedagógicas justas, inclusivas, dialogando e respeitando a dignidade dos aprendentes, sujeitos de sua cidadania em formação.

Quanto aos currículos, no âmbito conceitual, as concepções sobre currículo perfilam-se a teorizações tradicionais, críticas e pós-críticas 
que operam diferentes pressupostos, a partir dos quais podem ser planejadas trajetórias formativas diversas.

As teorias tradicionais operam os conceitos fundamentais de: "ensino, aprendizagem, avaliação, metodologia, didática, organização, planejamento, eficiência, objetivos” (SILVA, 2007, p. 17). Tais conceitos subsidiam modelos curriculares hegemônicos, etnocêntricos e supostamente neutros. Nessa linha, os currículos são entendidos como normatização, prescrição, centrados nos conteúdos disciplinares e/ou listas de objetivos. Esses modelos difundiram a ideia de currículo como equivalente à grade curricular (EYNG, 2010).

As teorias críticas operam os conceitos fundamentais de: "ideologia, reprodução cultural e social, poder, classe social, capitalismo, relações sociais de produção, conscientização, emancipação e libertação, currículo oculto, resistência" (SILVA, 2007, p. 17). Tais conceitos subsidiam a compreensão de que os currículos são ideologicamente situados e inseridos nas relações de poder, especialmente nos interesses das lutas de classe. Nessa linha, os currículos são entendidos como espaço de resistência, como forma de libertação da opressão econômico-capitalista e possibilidade de emancipação a partir da conscientização (EYNG, 2010, p. 36).

As teorias pós-críticas operam os conceitos fundamentais de: "identidade, alteridade, diferença, subjetividade, significação e discurso, saber-poder, representação, cultura, gênero, raça, etnia, sexualidade, multiculturalismo" (SILVA, 2007, p. 17). Nessa linha de teorização, os currículos atuam como práticas de subjetivação, de significação e discurso produzidos nas relações de saber-poder, sendo os currículos entendidos como formas de seleção e representação da cultura, compreendendo demandas das questões de gênero, raça, etnia, sexualidade, multiculturalismo. Os currículos produzem identidades heterogêneas e diversas, que num processo dialógico e ético possibilitam a emancipação a partir da cidadania ativa (EYNG, 2010, p. 37).

Evidentemente, as consequências na direção da justiça curricular, parâmetro para que a educação básica garanta o direito à educação de qualidade social, serão outras, em virtude das teorizações postas em prática nas 
instituições escolares. Ressalta-se, portanto, que cada abordagem teórica viabiliza e configura diferentes concepções e práticas de avaliação.

Quanto aos processos avaliativos, os estudos de Dias Sobrinho (2001) têm chamado a atenção sobre a plurirreferencialidade: complexidade, polissemia do conceito de avaliação, operando com múltiplas e heterogêneas referências. Os conceitos são elaborados e consubstanciam em diferentes concepções sobre avaliação, no âmbito de quatro gerações de avaliação, sendo as duas primeiras mais alinhadas à perspectiva conservadora. Em sua primeira geração, no início do século XX, foi compreendida como medida de resultados; em sua segunda geração, entre os anos 1930 e 1950, definiu-se em termos de alcance de objetivos (LEITE, 2006, p. 461).

Dessa perspectiva conservadora emanam as abordagens positivista e regulatória de avaliação. A abordagem positivista tem como pressuposto epistemológico a neutralidade. Acredita, portanto, que "A avaliação é científica com apoio em ciência neutra, fora das relações de poder e das particularidades que poderiam influenciar contextos" (LEITE, 2006, p. 487). A abordagem regulatória opera com pressupostos economicistas da eficiência, cujos indicadores estão fortemente definidos nas atuais políticas e práticas de avaliação em larga escala.

A perspectiva transformadora emerge da terceira geração e fortalece-se na quarta geração da avaliação, sendo que

[...] a terceira geração, desde os anos 1960, entende a avaliação como juízo ou apreciação de mérito ou valor de alguma coisa; a quarta geração conceitua a avaliação como uma construção da realidade, uma atribuição de sentidos, influenciada pelos contextos e pelos valores intervenientes (LEITE, 2006, p. 461).

Alinhadas a essa perspectiva, temos quatro abordagens: fenomenológica, crítico-marxista, emergente e emancipatória.

Nos pressupostos da fenomenologia, temos uma importante virada. "Os conceitos centrais desse enfoque são a intersubjetividade, o motivo e a razão dos sujeitos" (LEITE, 2006, p. 488). 
A abordagem crítico-marxista assume pressupostos epistemológicos da dialética, que considera o homem em sua historicidade e capacidade de influir e transformar as circunstâncias da realidade: "o conhecimento, em sua condição dialética, se produz a partir da compreensão do mundo social, onde coexistem a negação e a contradição e as manifestações da consciência dos sujeitos como produto de seu ser social" (LEITE, 2006, p. 488).

Os pressupostos da abordagem emergente aproximam-se da concepção da complexidade, da diversidade ao considerar que "existem tantos conhecimentos quantas práticas sociais existirem, por isto, a avaliação emprega os conhecimentos da ciência juntamente com os saberes dos sujeitos epistêmicos" (LEITE, 2006, p. 488).

A abordagem emancipatória orienta-se nos pressupostos democráticos, da justiça social. A expressão avaliação emancipatória é encontrada nas pesquisas educacionais no Brasil, tendo como referência os estudos desenvolvidos por Ana Maria Saul, em sua pesquisa de tese de doutoramento em 1985 e publicada em 1988. A autora elabora os referenciais que subsidiam uma avaliação na perspectiva crítica, incorporando os princípios da educação libertadora, da conscientização em Paulo Freire (1980) e assume três vertentes teórico-metodológicas inspiradoras na construção da concepção da avaliação emancipatória que defende: "a primeira delas caracteriza-se como avaliação democrática; a segunda é a crítica institucional e criação coletiva; e a terceira é a pesquisa participante" (SAUL, 1988, p. 53). Explicita, ainda, que "A avaliação emancipatória tem dois objetivos básicos: iluminar o caminho da transformação e beneficiar as audiências no sentido de torná-las autodeterminadas" (SAUL, 1988, p. 61).

A avaliação emancipatória vincula-se à práxis, ao planejamento que supõe a projeção de futuro, com vistas ao desenvolvimento de ações estratégicas que efetivem as intencionalidades pedagógicas pretendidas, na busca da qualidade social. 


\section{Garantia do direito à educação de qualidade social via avaliação emancipatória}

Educação de qualidade social expressa a concepção do direito à educação, que não se trata apenas do acesso à escola, mas também da permanência e, como resultado, de uma formação de qualidade. Assim, o direito à educação consubstancia-se na efetivação de um processo educativo significativo para cada sujeito historicamente situado. Portanto, não se trata de direito à qualquer educação, mas a uma educação de qualidade, independente da origem social, econômica ou cultural. Ressalta, também, a indicação da necessidade de a educação escolar considerar todos de modo igualitário e cada um em sua diversidade e individualidade.

Essa consideração não tem sido característica preponderante na educação escolar. Historicamente, predominam práticas alinhadas a discursos conservadores, da racionalidade científica, da neutralidade e da centralidade dos conteúdos, assentes nas lógicas educativas tradicionais, atravessados por apelos atuais da racionalidade empresarial e mercantil, pautados nas lógicas quantitativas da eficiência econômica.

A almejada qualidade social da educação pauta-se na lógica pedagógica e social, objetivando respectivamente a eficácia e a efetividade com vistas à relevância social, no atendimento às necessidades formativas. Os critérios que parametrizam a qualidade eficiência, eficácia, efetividade, equidade, a exemplo de inúmeros conceitos no campo educacional, são polissêmicos e diversos. No caso do conceito da eficácia, embora fortemente vinculado ao paradigma economicista e eficientista, consideramos uma das faces da eficácia da educação mais relacionadas à perspectiva emancipatória que se refere a "sua capacidade de alcançar objetivos sociais, econômicos, e políticos que lhe são atribuídos" (MONS, 2011, p. 296). Portanto, os conceitos de eficácia e eficiência são complementares, mas 
insuficientes para a compreensão da qualidade da educação, pois necessitam ser operados com o conceito de igualdade.

A igualdade que queremos construir assume o reconhecimento dos direitos básicos de todos. No entanto, esses todos não são padronizados, não são os "mesmos". Têm que ter as suas diferenças reconhecidas como elementos presentes na construção da igualdade (CANDAU, 2005, p. 128-129).

Assim, a análise da eficácia e da eficiência é acompanhada "de um terceiro instrumento: a mensuração das desigualdades, segundo diferentes critérios (sexo, grupos sociais, étnicos, territoriais)" (MONS, 2011, p. 300). Nesse sentido, a avaliação da qualidade social pauta-se e promove o diálogo e o equilíbrio entre os critérios da igualdade, da efetividade, da eficácia e da eficiência. De preferência nessa ordem, assumindo a avaliação emancipatória inscrita "numa vertente político-pedagógica cujo interesse primordial é emancipador, ou seja, libertador, visando provocar a crítica, de modo a libertar o sujeito de condicionamentos deterministas" (SAUL, 1988, p. 61).

Essa perspectiva de avaliação tem por finalidade a emancipação, ou seja, a capacidade de auto-organização, o governo de si, a partir da libertação da heterodeterminação, do governo dos outros sobre si (FOUCAULT, 2010). "O compromisso principal dessa avaliação é o de fazer com que as pessoas, direta ou indiretamente envolvidas em uma ação educacional, escrevam sua 'própria história' e gerem as suas próprias alternativas de ação" (SAUL, 1988, p. 61).

Portanto, a avaliação emancipatória, numa abordagem curricular pós-crítica, intercultural, assegura o direito fundamental de acesso à possibilidade de uma formação de qualidade social.

A garantia de direitos constitui-se valor universal. Mas embora entendidos como universais em concepções largamente difundidas, sobretudo, desde a Declaração Universal dos Direitos Humanos, em 1948, "é sabido que os direitos humanos não são universais na sua aplicação" (SANTOS, 2010, p. 442). Os Direitos Humanos "emergem gradualmente das lutas que 
o homem trava por sua própria emancipação e das transformações das condições de vida que essas lutas produzem" (BOBBIO, 2004, p. 51).

O movimento sócio-histórico, cultural e econômico incide na configuração do que hoje entendemos e temos como políticas de direitos humanos. Com destaque à Resolução 1 (BRASIL, 2012), que estabelece as diretrizes para a educação em direitos humanos, eles são entendidos como "[...] um conjunto de direitos civis, políticos, sociais, econômicos, culturais e ambientais, sejam eles individuais, coletivos, transindividuais ou difusos, referem-se à necessidade de igualdade e de defesa da dignidade humana" (BRASIL, 2012).

A efetivação da perspectiva emancipatória de direitos humanos requer "uma política de direitos humanos radicalmente diferente da liberal hegemônica", mas desde que "tal política for concebida como parte de uma constelação mais ampla pela emancipação social” (SANTOS, 2010, p. 443).

Os direitos humanos, do ponto de vista histórico, carregam e traduzem na realidade uma utopia. Nesse sentido se convertem numa plataforma emancipatória em reação e em repúdio às formas de exclusão, desigualdade, opressão, subalternização e injustiça (CANDAU et al., 2013, p. 47).

A garantia do direito, como possibilidade emancipatória, requer uma política contra-hegemônica, considerando a efetivação da qualidade social para todos e todas.

A constituição desses referenciais políticos incide na discussão dos conceitos, dentre eles, a qualidade, pois tem-se constituído elemento definidor das políticas educacionais. Pela via das políticas de avaliação, a qualidade educacional tem sido parametrizada pelo conceito de qualidade da política liberal hegemônica, orquestrada pelo setor econômico. Por essa via, a preocupação básica tem sido o rendimento quantitativo dos alunos.

Mas a qualidade educacional, na perspectiva emancipatória, vai além dos critérios econômicos eficientistas. A justiça social que se espera numa educação de qualidade requer condições que a sustentem e a 
garantam, considerando a interdependência das dimensões sociais, culturais, econômicas e pedagógicas.

O termo qualidade, no artigo $4^{\circ}$ da Lei de Diretrizes e Bases da Educação Nacional, está relacionado às condições de oferta da educação escolar pública, como dever do Estado, garantindo "padrões mínimos de qualidade de ensino, definidos como a variedade e quantidade mínimas, por aluno, de insumos indispensáveis ao desenvolvimento do processo de ensino-aprendizagem" (BRASIL, 1996). A ideia de qualidade é adjetivada, incorporando o termo social para sua designação, e então surge a denominação qualidade social na Resolução n. 4 (BRASIL, 2010), em seu art. 9, segundo o qual "A escola de qualidade social adota como centralidade o estudante e a aprendizagem, o que pressupõe atendimento aos seguintes requisitos". São listados, na legislação, nove requisitos necessários para a efetivação da qualidade social.

O primeiro requisito supõe a formação para e na práxis, ou seja, produção de ampla discussão coletiva sobre os referenciais que melhor subsidiam as intencionalidades educativas em cada contexto: "I - revisão das referências conceituais quanto aos diferentes espaços e tempos educativos, abrangendo espaços sociais na escola e fora dela" (BRASIL, 2010).

O segundo requisito supõe educação intercultural, via diálogo com a na diversidade: "II - consideração sobre a inclusão, a valorização das diferenças e o atendimento à pluralidade e à diversidade cultural, resgatando e respeitando as várias manifestações de cada comunidade" (BRASIL, 2010).

O terceiro requisito supõe efetivação da intencionalidade educativa referendada no PPP: "III - foco no projeto político-pedagógico, no gosto pela aprendizagem e na avaliação das aprendizagens como instrumento de contínua progressão dos estudantes" (BRASIL, 2010).

O quarto requisito supõe o desenvolvimento das propostas curriculares nas ações pedagógicas dos docentes, mediante gestão democrática da ação coletiva: "IV - inter-relação entre organização do currículo, do trabalho pedagógico e da jornada de trabalho do professor, tendo como objetivo a aprendizagem do estudante" (BRASIL, 2010). 
O quinto requisito supõe o fortalecimento da formação inicial e continuada dos profissionais da educação, considerando todos os sujeitos que atuam na escola: "V - preparação dos profissionais da educação, gestores, professores, especialistas, técnicos, monitores e outros" (BRASIL, 2010).

O sexto requisito supõe condições de trabalho e infraestrutura adequadas. "VI - compatibilidade entre a proposta curricular e a infraestrutura entendida como espaço formativo dotado de efetiva disponibilidade de tempos para a sua utilização e acessibilidade" (BRASIL, 2010).

O sétimo requisito supõe ampliação de sujeitos com participação nos processos de gestão democrática, inserindo agentes externos ao cotidiano escolar nos esforços em prol da melhora da educação: "VII - integração dos profissionais da educação, dos estudantes, das famílias, dos agentes da comunidade interessados na educação" (BRASIL, 2010).

O oitavo requisito supõe a melhora das condições de formação, atuação profissional e de remuneração dos professores: "VIII - valorização dos profissionais da educação, com programa de formação continuada, critérios de acesso, permanência, remuneração compatível com a jornada de trabalho definida no projeto político-pedagógico" (BRASIL, 2010).

O nono requisito supõe a realização e o fortalecimento de parcerias, objetivando a ampliação de recursos e de espaços formativos disponíveis: "IX - realização de parceria com órgãos, tais como os de assistência social e desenvolvimento humano, cidadania, ciência e tecnologia, esporte, turismo, cultura e arte, saúde, meio ambiente" (BRASIL, 2010).

Considerando o atendimento desses nove requisitos, a escola de qualidade social assume como critérios e subsídios os quatro fatores assinalados por Silva (2009, p. 224), que atuam como condicionantes para a garantia de direitos numa educação justa, democrática e emancipatória.

1. Fatores socioeconômicos, considerando a garantia de direitos fundamentais de moradia, alimentação, trabalho e educação.

2. Fatores socioculturais, considerando a garantia de direitos relacionados à escolarização, cultura e lazer. 
3. Fatores financeiros, considerando a garantia do direito ao financiamento público adequado, com participação coletiva na aplicação desses recursos de modo ético e transparente.

4. Fatores pedagógico-formativos, considerando a garantia do direito a formadores qualificados e atualizados, abrangendo o compromisso dos gestores centrais com a formação dos docentes e demais profissionais da educação.

Portanto, o conjunto de fatores socioeconômicos, socioculturais, financeiros e pedagógico-formativos viabilizam a garantia de um conjunto de direitos implicados numa educação justa, capaz de induzir a conquista do direito à educação básica de qualidade social para todos. Isso "[...] implica igualmente a alteração, entre outras variáveis organizacionais, da concepção dominante de cultura escolar, de modo a dar-lhe um cunho mais político" (ESTÊVÃO, 2013, p. 23). Considerando uma cultura escolar que se paute nos requisitos encontrados em Estêvão (2013, p. 23-24):

- facilite-nos a reaprendizagem da dependência do outro, sem nos transformarmos em seus escravos;

- dê-nos a todos a possibilidade de justificar e de argumentar as nossas posições, dentro de uma ordem escolar não repressiva e de uma razão não beligerante; não nos impeça de praticar a alegria de viver;

- conduza-nos a aprender a cooperar, a partilhar, a respeitar diferenças, a ser solidários, a estar juntos;

- favoreça a nossa compreensão do trabalho escolar para além do rendimento acadêmico ao mesmo tempo que obste à criação de barreiras entre os que sabem e os que não sabem;

- exija-nos a prática de uma pedagogia diferenciada no desenvolvimento de um currículo comum que pratique estratégias diversificadas de aprendizagem;

- motive-nos a partilhar o poder e a fomentar a participação, pois aquilo que se considera próprio defende-se e respeita-se normalmente mais; 
- eduque-nos para a autonomia, que não anule a rebeldia contra a fatalidade nem a rigorosidade ética;

- ensine-nos a sermos exigentes e eficazes, não aceitando uma qualidade corrompida;

- celebre a amizade, a cooperação e a fidelidade às pessoas.

Estêvão (2013, p. 24) conclui afirmando que se trata, pois, "de uma concepção de cultura que encerra em si várias culturas ou subculturas, profundamente respeitadora(s) dos direitos e em que o próprio conhecimento é entendido igualmente como uma forma de reconhecimento".

A garantia do direito à educação de qualidade social supõe parceria, reciprocidade, diálogo da/na/entre a diversidade.

\section{O direito de expressão e do respeito na educação de qualidade social}

$\mathrm{Na}$ convenção internacional sobre os direitos da criança (UNESCO, 1989), é garantido "à criança capaz de discernimento o direito de exprimir livremente sua opinião em toda questão que lhe interesse" (art. 12). Entretanto, as concepções de currículo e avaliação que se desenvolvem em grande parte das escolas não garantem aos estudantes o direito de expressão.

Manifesta-se nas diferentes vozes, de diferentes sujeitos, a violação do direito ao respeito, ao assinalarem um forte anseio por esse direito, como o mais importante a ser conquistado.

Essa constatação está referendada nos resultados das pesquisas realizadas pelo grupo de pesquisadores do Observatório de Violências nas Escolas da Pontifícia Universidade Católica do Paraná (PUCPR), que desenvolve suas atividades desde 2004.

Nas Tabelas 1 e 2 estão as respostas de crianças e adolescentes, estudantes de 14 escolas públicas municipais e estaduais, localizadas em bairros de grande vulnerabilidade social de sete municípios, abrangendo Curitiba e mais seis municípios da região metropolitana. Em cada 
município, foram selecionadas duas escolas: uma municipal e outra estadual, num mesmo bairro. A coleta de dados foi realizada via aplicação de entrevistas individuais estruturadas.

Diante da pergunta aberta "o que você considera como direito fundamental da pessoa?", as respostas evidenciam uma ampla constelação de direitos valorizados pelos participantes, os quais necessitam de proteção, pois ainda não estão suficientemente garantidos. Segundo posicionamentos dos estudantes, embora suas expectativas estejam distribuídas pelos diferentes direitos, o respeito é o mais importante.

Tabela 1 - Percepções sobre direitos distribuídas por idade - questão aberta

\begin{tabular}{|c|c|c|c|c|c|c|c|c|}
\hline \multirow[t]{2}{*}{ Categorias } & \multicolumn{2}{|c|}{8 a 10} & \multicolumn{2}{|c|}{11 a 13} & \multicolumn{2}{|c|}{14 a 16} & \multicolumn{2}{|c|}{ Total } \\
\hline & N. & $\%$ & N. & $\%$ & N. & $\%$ & N. & $\%$ \\
\hline Respeito, não discriminação & 58 & 23,8 & 82 & 28,8 & 6 & 31,6 & 146 & 26,6 \\
\hline Educação, estudar, escola, aprender & 62 & 25,4 & 73 & 25,6 & 2 & 10,5 & 137 & 25,0 \\
\hline $\begin{array}{l}\text { Básicos: moradia saúde, alimentação, } \\
\text { saneamento, água, luz, transporte, } \\
\text { vestuário, segurança }\end{array}$ & 46 & 18,9 & 36 & 12,6 & 3 & 15,7 & 85 & 15,5 \\
\hline Liberdade, ser livre, expressão & 10 & 4,1 & 17 & 6,0 & 1 & 5,5 & 28 & 5,1 \\
\hline $\begin{array}{l}\text { Amizade, carinho, bondade, amor, } \\
\text { felicidade, atenção }\end{array}$ & 17 & 7,0 & 9 & 3,2 & 1 & 5,5 & 27 & 4,9 \\
\hline Emprego, trabalho & 7 & 2,9 & 9 & 3,2 & 1 & 5,5 & 17 & 3,1 \\
\hline Brincar, esporte, lazer & 3 & 1,2 & 9 & 3,2 & 0 & 0 & 12 & 2,2 \\
\hline Internet, computador, livros, leitura & 1 & 0,4 & 7 & 2,4 & 1 & 5,5 & 9 & 1,6 \\
\hline Vida & 7 & 2,9 & 1 & 0,3 & 0 & 0 & 8 & 1,5 \\
\hline
\end{tabular}


Tabela 1 - Percepções sobre direitos distribuídas por idade - questão aberta

(Conclusão)

\begin{tabular}{|c|c|c|c|c|c|c|c|c|}
\hline \multirow[t]{2}{*}{ Categorias } & \multicolumn{2}{|c|}{8 a 10} & \multicolumn{2}{|c|}{11 a 13} & \multicolumn{2}{|c|}{14 a 16} & \multicolumn{2}{|c|}{ Total } \\
\hline & N. & $\%$ & N. & $\%$ & N. & $\%$ & $\mathbf{N}$. & $\%$ \\
\hline Igualdade, cidadania, participação & 3 & 1,2 & 3 & 1,0 & 0 & 0 & 6 & 1,0 \\
\hline Convivência familiar e comunitária & 1 & 0,4 & 4 & 1,4 & 0 & 0 & 5 & 0,9 \\
\hline Qualidade de vida, dignidade & 4 & 1,6 & 1 & 0,3 & 0 & 0 & 5 & 0,9 \\
\hline Honestidade, caráter, confiança & 1 & 0,4 & 3 & 1,0 & 0 & 0 & 4 & 0,7 \\
\hline Futuro & 0 & 0 & 1 & 0,3 & 0 & 0 & 1 & 0,2 \\
\hline Bolsa Família & 1 & 0,4 & 0 & 0 & 0 & 0 & 1 & 0,2 \\
\hline Não sei & 23 & 9,4 & 30 & 10,5 & 4 & 21,1 & 57 & 10,4 \\
\hline Total & 244 & 100 & 285 & 100 & 19 & 100 & 548 & 100 \\
\hline
\end{tabular}

Fonte: Dados da pesquisa.

Embora tenha sido um pequeno número, não deixa de ser significativo que $10,4 \%$ dos estudantes tenham manifestado surpresa e desconhecimento, respondendo simplesmente "não sei" ou se mantendo em silêncio. Esse é um forte indicativo de que essas reflexões precisam ser asseguradas no espaço escolar e social.

Mas o mais preocupante são os indícios de violação de direitos. Observa-se que quanto mais tempo os estudantes são submetidos a regimes curriculares e práticas avaliativas, enfim, quanto mais convivem nas escolas, mais percebem a necessidade do respeito que não lhes é assegurado, ou seja, ao aumentar a experiência escolar, também aumenta a consciência da falta de garantia do direito de ser respeitado. 
Em seguida, na entrevista, foi apresentada uma listagem de direitos previstos na legislação e uma questão fechada: "Qual você considera mais importante?".

Novamente, as respostas de crianças e adolescentes indicam um direito fundamental para a garantia da dignidade humana: o respeito.

Tabela 2 - Percepções sobre direitos distribuídas por idade - questão fechada

\begin{tabular}{|c|c|c|c|c|c|c|c|c|}
\hline \multirow[t]{2}{*}{ Categorias } & \multicolumn{2}{|c|}{8 a 10} & \multicolumn{2}{|c|}{11 a 13} & \multicolumn{2}{|c|}{14 a 16} & \multicolumn{2}{|c|}{ Total } \\
\hline & N. & $\%$ & N. & $\%$ & N. & $\%$ & N. & $\%$ \\
\hline Respeito & 67 & 25,9 & 65 & 23,6 & 8 & 40,0 & 140 & 25,2 \\
\hline Saúde, alimentação & 68 & 26,3 & 55 & 19,9 & 2 & 10,0 & 125 & 22,5 \\
\hline $\begin{array}{l}\text { Convivência familiar e } \\
\text { comunitária }\end{array}$ & 28 & 10,8 & 38 & 13,8 & 1 & 0,5 & 67 & 12,1 \\
\hline Vida & 27 & 10,5 & 37 & 13,4 & 1 & 0,5 & 65 & 11,7 \\
\hline Educação & 32 & 12,4 & 26 & 9,4 & 1 & 0,5 & 59 & 10,6 \\
\hline Liberdade & 12 & 4,6 & 19 & 6,9 & 3 & 15,0 & 34 & 6,1 \\
\hline Esporte, lazer & 13 & 5,0 & 6 & 2,2 & 1 & 0,5 & 21 & 3,7 \\
\hline Dignidade & 4 & 1,5 & 12 & 4,3 & 1 & 0,5 & 17 & 3,0 \\
\hline Cultura & 4 & 1,5 & 10 & 3,6 & 0 & 0 & 14 & 2,5 \\
\hline Profissionalização & 2 & 0,8 & 5 & 1,8 & 2 & 10,0 & 9 & 1,6 \\
\hline Não resposta & 2 & 0,8 & 3 & 1,0 & 0 & 0 & 5 & 0,9 \\
\hline Total & 259 & 100 & 276 & 100 & 20 & 100 & 556 & 100 \\
\hline
\end{tabular}

Fonte: Dados da pesquisa. 
O respeito constitui-se um direito fundamental, conforme estabelece o Estatuto da Criança e do Adolescente (ECA), no art. 15: "A criança e o adolescente têm direito à liberdade, ao respeito e à dignidade como pessoas humanas em processo de desenvolvimento e como sujeitos de direitos civis, humanos e sociais garantidos na Constituição e nas leis" (BRASIL, 1990). No art. 17, do mesmo estatuto, está especificado no que consiste o direito ao respeito. "O direito ao respeito consiste na inviolabilidade da integridade física, psíquica e moral da criança e do adolescente, abrangendo a preservação da imagem, da identidade, da autonomia, dos valores, ideias e crenças, dos espaços e objetos pessoais" (BRASIL, 1990).

A escola constitui-se no espaço onde se aprende a conhecer e vivenciar os direitos de cidadania; porém, esse espaço tem negado esse conhecimento e essa vivência. E isso não é exclusivo dos estudantes. Embora não sejam apresentadas aqui as respostas dos professores, vale destacar que entre eles o direito mais assinalado é também o respeito. Assim, a maior expectativa de direito de estudantes e professores é nominalmente a mesma, contudo o que ambos os grupos esperam como evidência da garantia desse direito é diametralmente oposto.

Existe aí um conflito de gerações? Conflito na visão de papéis? $\mathrm{Na}$ concepção de direitos? Ao serem indagados sobre como esse direito poderia ser assegurado, os estudantes indicam que entendem o respeito como direito a terem voz, poderem falar e serem ouvidos por seus educadores; por outro lado, os professores entendem que estarão usufruindo do respeito quando os estudantes se mantiverem quietos, ficarem em silêncio. Sem dúvida, falta diálogo, entretanto, vale assinalar que a garantia de direitos de estudantes e de professores é viabilizada concomitantemente.

\section{Considerações finais}

O diálogo entre educadores e educandos no currículo precisa ser mediado pela compreensão de direitos, deveres e responsabilidades de cada um na escola e na sociedade. "Contrariamente ao que se poderia pensar, o 
direito de expressão dos alunos é juridicamente mais amplo do que o dos professores" (MERLE, 2011, p. 237). O direito de expressão almejado pelos estudantes compreende ampla participação nas decisões que se materializam na vida escolar. "As questões relativas à pedagogia, às sanções, à organização das provas e às práticas de avaliação pertencem totalmente ao domínio do direito de expressão dos alunos" (MERLE, 2011, p. 237).

Entretanto, o direito à expressão não se concretiza nas relações educativas, no currículo, nem nas práticas de avaliação. Nos resultados das pesquisas desenvolvidas na trajetória do grupo do Observatório de Violências nas Escolas, têm sido acentuados os traços da invisibilidade dos interesses e das necessidades de crianças e adolescentes, além do silenciamento das vozes infantis e juvenis no processo educativo.

Crianças, adolescentes e jovens continuam sendo submetidos a regimes escolares autoritários, excludentes, que operam os pressupostos da padronização e da homogeneização de identidades.

As práticas educativas são configuradas sob traços muito fortes das concepções tradicionais de currículo e das concepções positivistas e regulatórias de avaliação, embora pressupostos das concepções críticas e pós-críticas de currículo e da perspectiva emancipatória estejam referendados nas políticas educacionais. Fragmentos dessas teorizações são enunciados nos discursos que atravessam os contextos educativos, mas ainda não estão suficientemente presentes nas práticas formativas em desenvolvimento.

Essas constatações ressaltam a urgência da garantia do direito de expressão, do diálogo com grupos infantis e juvenis como possibilidade para ressignificar a escola como espaço de garantia de direitos e diálogo com a diversidade cultural, incluindo a igualdade/diferença de gênero, raça, etnia, orientação e identidade sexual nas práticas curriculares.

Nessa perspectiva, faz-se necessário conhecer, valorizar e agir na promoção de estratégias e espaços de diálogo, de interlocução, que possibilitem que crianças, adolescentes e jovens tenham garantidos os direitos amplamente afirmados em leis, convenções e declarações.

A proteção e a garantia do direito à educação de qualidade social convertem-se em princípio de justiça social, sobretudo em contextos tão 
marcados pela desigualdade e pela exclusão, tal como temos no Brasil. Nessa direção, as pesquisas que desenvolvemos têm visam ao diagnóstico sobre questões relativas aos direitos e suas implicações na qualidade social da educação. Para tanto, a escola é compreendida como espaço vital na garantia de direitos, via diálogo com/na diversidade cultural, para a efetivação da educação intercultural em direitos humanos.

O desafio que se estende está em encontrar os caminhos para que a educação seja verdadeiramente capaz de dialogar com/na diversidade, via educação em direitos humanos de crianças, adolescentes e jovens como cidadãos conscientes e éticos. Essa é uma tarefa coletiva. Promover a justiça social, o respeito, o diálogo, a solidariedade na educação básica de qualidade social são grandes desafios da atualidade, aos quais nos vinculamos.

\section{Referências}

BOBBIO, N. A era dos direitos. Rio de Janeiro: Elsevier, 2004.

BRASIL. Lei n. 8.069, de 13 de julho de 1990. Dispõe sobre o Estatuto da Criança e do Adolescente e dá outras providências. Diário Oficial [da] República Federativa do Brasil, Brasília, DF, 14 jul. 1990. Disponível em: <http://www.planalto.gov.br/ ccivil_03/leis/18069.htm>. Acesso em: 13 fev. 2015.

BRASIL. Lei n. 9.394, de 20 de dezembro de 1996. Estabelece as diretrizes e bases da educação nacional. Diário Oficial [da] República Federativa do Brasil, Brasília: DF, 23 dez. 1996. Disponível em: <http://www.cpt.com.br/ldb/lei-de-diretrizes-e-bases-da-educacao-completa-interativa-e-atualizada〉. Acesso em: 10 ago. 2014.

BRASIL. Resolução n. 4, de 13 de julho de 2010. Define Diretrizes Curriculares Nacionais Gerais para a Educação Básica. Diário Oficial [da] República Federativa do Brasil, Brasília, DF, 14 jul. 2010a. Disponível em: <http://portal.mec.gov. br/index.php?Itemid=866\&id=14906\&option=com_content\&view=article $>$. Acesso em: 10 ago. 2014. 
BRASIL. Ministério da Educação. Conselho Nacional de Educação. Resolução n. 1, de 30 de maio de 2012. Estabelece Diretrizes Nacionais para a Educação em Direitos Humanos. Diário Oficial [da] República Federativa do Brasil, Brasília, DF, 31 maio 2012. Seção 1, página 48. Disponível em: <http://www.udesc.br/arquivos/id_submenu/83/rcp001_12.pdf >. Acesso em: 13 fev. 2015.

CANDAU, V. M. (Org.). Cultura(s) e educação: entre o crítico e o pós-crítico. Rio de Janeiro: DP\&A, 2005.

CANDAU, V. M. et al. Educação em direitos humanos e formação de professores(as). São Paulo: Cortez, 2013.

DIAS SOBRINHO, J. Educação e avaliação: técnica e ética. In: DIAS SOBRINHO, J.; RISTIOFF, D. I. Avaliação democrática: para uma universidade cidadã. Florianópolis: Insular, 2001.

ESTEVÂO, C. V. Direitos humanos, justiça social e educação pública. Repensar a escola pública como um direito na era dos mercados. In: EYNG, A. M. (Org.). Direitos humanos e violências nas escolas: desafios e questões em diálogo. Curitiba: CRV, 2013.

EYNG, A. M. Currículo escolar. 2. ed. rev. e atual. Curitiba: Ibpex, 2010.

FOUCAULT, M. Governo de si e dos outros. São Paulo: Martins Fontes, 2010.

FREIRE, P. Conscientização: teoria e prática da libertação, uma introdução ao pensamento de Paulo Freire. São Paulo: Moraes, 1980.

LEITE, D. Avaliação da educação superior. In: MOROSINI, M. C. (Ed.). Enciclopédia de pedagogia universitária: glossário. Brasília: INEP; RIES, 2006. v. 2. p. 459-506. MERLE, P. Direitos dos alunos. In: ZANTEN, A. V. (Coord.). Dicionário de educação. Petrópolis: Vozes, 2011.

MONS, N. Eficácia dos sistemas educativos. In: ZANTEN, A. V. (Coord.). Dicionário de educação. Petrópolis: Vozes, 2011. 
ORGANIZAÇÃO DAS NAÇÕES UNIDAS - ONU. Convenção internacional dos direitos da criança. 1989. Disponível em: <https://www.unicef.pt/docs/pdf_publicacoes/convencao_direitos_crianca2004.pdf /doc_crianca.php/>. Acesso em: 20 out. 2010.

SANTOS, B. S. A gramática do tempo: para uma nova cultura política. 3. ed. São Paulo: Cortez, 2010.

SILVA, M. A. Qualidade social da educação pública: algumas aproximações. Cad. Cedes, v. 29, n. 78, p. 216-226, 2009.

SILVA, T. T. Documentos de identidade: uma introdução às teorias do currículo. 2. ed. 11. reimp. Belo Horizonte: Autêntica, 2007.

SAUL, A. M. Avaliação emancipatória: desafios à teoria e à prática de avaliação e reformulação de currículo. 2. ed. São Paulo: Cortez, 1988.

Recebido: 09/12/2014

Received: 12/09/2014

Aprovado: 20/12/2014 Approved: 12/20/2014 
